the left. X-ray revealed absence of the tubular bones of the metacarpals and phalanges bilaterally. The feet showed similar abnormalities. There was micrognathia, glossoptosis, cleft soft palate and tracheomalacia. Eyes and fundi were normal. The baby expired after numerous apneic spells associated with cyanosis.

Baby boy $\mathrm{D}$ was born at term to a 29-year-old mother who was hospitalized for schizophrenia during the pregnancy; she showed intermittent glucosuria. The infant exhibited micrognathia, shortening of the right femur and bilateral club feet. X-rays showed the cortex of the femurs to be abnormally thick, and defects were noted in the vertebral bodies of the lower lumbar column. Ocular fundi were normal. The baby expired after a gastrostomy and repeated apneic episodes.

Cytogenetic studies on both patients were normal. Our two patients, together with the previously reported two cases [Passarge, Lancet $i: 324,1965$; Centa and Rover, Pathologica 57: 245, 1965] appear to represent a distinct syndrome.

27 Development of Transsulfuration in the Human Fetus, Premature and Newborn: Clinical Implications. Gerald Gaull, John Sturman and Niels Raiha, Dept. of Ped. Res., N.Y.S. Inst. Basic Res. Ment. Retard., Dept. Ped., Mt. Sinai Hosp. Sch. Med., New York, and Depts. Clin. Chem. and Obst. and Gyn., Univ. Helsinki (introduced by Horace Hodes).

In the human adult, $90 \%$ of ingested methionine is converted to cystine, a nonessential amino acid. The ability to make this conversion was investigated in the developing human. Enzymes on the pathway of conversion of methionine to cystine in the liver of 24 fetuses (2.5-20.5 cm crown rump length), three prematures and one full-term newborn were assayed. Cystathionase activity was undetectable, and administration of massive doses of vitamin $\mathrm{B}_{6}$ to the mother had no effect on this activity in three fetuses. Cystathionine, the substrate of cystathionase, not normally present in measurable quantities in adult human liver (which has considerable activity of cystathionase) was present in large concentrations. Considerable activity of methionine-activating enzyme was present $(2 / 3$ of adult $)$; cystathionine synthase activity was also present $(1 / 3-1 / 2$ of adult). A similar pattern of transsulfuration enzymes was seen in brain, but there are no antemortem adult controls for comparison. The concentration of cystathionine in whole brain was constant during this period and, in contrast to the adult, well below the concentration in liver. The placenta cannot subserve the transsulfuration function for the fetus, since the enzymatic mechanism was absent. Fetal rat liver, in contrast, is able to convert methionine to cystine. Thus, cystine may be an essential amino acid until sometime after birth, and the human fetus is entirely dependent upon the mother for its supply of cystine for protein synthesis. The implications for infant nutrition and metabolic screening will be discussed.

Chloramphenicol Causes Ultrastructural and Biochemical Alterations in Developing Chick Liver. J.B.Warshaw, Harvard Med. Sch., Massachusetts Gen. Hosp., Children's Service and the Shriners Burns Institute, Boston.

Chloramphenicol (Ch) administration has been associated with the fetal 'gray baby syndrome' and depression of the hematopoetic system. Ch also causes alterations of mitochondrial morphology and inter- feres with mitochondrial energy metabolism in a variety of species. We have investigated the effects of $\mathrm{Ch}$ on mitochondrial energy metabolism and structure in the developing chick liver. $\mathrm{Ch}$ and ${ }^{14} \mathrm{C}$-leucine were injected through shell windows into 12 to 17 day chick embryos. After 3 days of exposure to the drug the livers were fixed for electron microscopy and were also used for biochemical studies. Electron micrographs of the Ch treated livers showed major ultrastructural alterations characterized by profound mitochondrial swelling and distortions of mitochondrial structure. There was also a great abundance of free ribosomes. The cytochrome oxidase activity of the treated liver homogenates and the mitochondrial yields from $\mathrm{Ch}$ treated livers were approximately 40 to $50 \%$ of those of the controls. Mitochondrial profiles of $\mathrm{Ch}$ treated liver homogenates on sucrose density gradients were greatly diffused when compared with controls, presumably because of the ultrastructural abnormalities. ${ }^{14} \mathrm{C}$ leucine incorporation into the $\mathrm{Ch}$ treated liver mitochondria separated on a sucrose density gradient was significantly less than observed with controls. Those mitochondria which were isolated had some biochemical activities similar to the controls (isocitric dehydrogenase, malate dehydrogenase) but rates of oxidation with NADH limited substrates were less than control values. These data suggest that $\mathrm{Ch}$ may interfere with energy metabolism in rapidly proliferating tissues because of its effects on protein synthesis and mitochondrial structure and function.

29 The Metabolism and Transplacental Passage of $3 \mathrm{H}$ Vitamin D3 in the Pregnant Primate, Macaca mulatta. Henry Rrkkers, Univ. of Wisconsin Med. Sch., Dept. of Ped., Madison, Wisc. (introduced by C. C. Lobeck).

In animal systems excessive maternal ingestion of vitamin $\mathrm{D}$ during pregnancy has been shown to cause in the offspring most of the bony and arterial pathology seen in idiopathic hypercalcemia of infancy. This disease is felt by some to be due to altered responsiveness of the fetus and/or mother to vitamin D. Mammals, including man, convert vitamin $\mathrm{D}$ to 25 -hydroxy vitamin $\mathrm{D}$ before the vitamin has its characteristic effects. A previous study demonstrated nonspecific antirachitic activity in cord serum of rabbits whose mothers had been given massive vitamin $D$ doses during pregnancy. The current study demonstrates not only how much, but also, in what metabolic form the vitamin traverses the placenta.

C-sections were performed $6,24,48$ and $100 \mathrm{~h}$ after IV administration of $3 \mathrm{H}$ - vitamin D 3 in non-physiologic doses to pregnant rhesus monkeys. All tissues within the fetal compartment were studied for the amount and metabolic state of the vitamin present. Results show that the placenta acts as a barrier and storage organ from which the fetal serum somewhat selectively supplies fetal tissues with, mainly, 25-hydroxy vitamin D. Fetal tissues do not appear to convert vitamin D to 25 -hydroxy vitamin $\mathrm{D}$. The data suggest that at physiologic doses the fetal tissues would probably not be exposed to unaltered vitamin $\mathrm{D}$. This suggests that the teratogenicity of vitamin $\mathrm{D}$ is due to undue exposure of fetal tissues to the unaltered vitamin.

Early Mammalian Development: Nucleoside Transport and RNA Synthesis. DonNA L. DAEnTL and Charles J. Epstein, Univ. of California, Dept. of Ped., San Francisco. 
For studying early development, the mouse embryo provides a convenient experimental model. Of particular interest is the transition from the cleavage (day 2) to the blastocyst (day 3 ) stage of development, a period of concurrent morphologic and molecular change. In addition to striking alterations in the activities of several enzymes, there is a marked change in the capacity of embryos incubated in vitro to take up uridine, a nucleoside precursor of RNA. The incorporation of ${ }^{3} \mathrm{H}$-uridine into the acid soluble pool follows MichaelisMenten kinetics, and the maximal uptake $\left(V_{\max }\right)$ is 8 -fold greater in day 3 than in day 2 embryos. During the same time there is also an increase in the incorporation of ${ }^{3} \mathrm{H}$-uridine into embryonic RNA. To distinguish a real increase in RNA synthetic capacity from an apparent increase resulting from greater precursor uptake, embryos were incubated in the presence of varying concentrations of ${ }^{3} \mathrm{H}$-uridine. In day 3 embryos, saturation of the RNA synthetic system occurs prior to saturation of the transport system, and incorporation of uridine into RNA is independent of precursor concertration $\geq 1 \mu \mathrm{M}$. However, this is not the case in day 2 embryos: uridine incorporation into RNA parallels the uptake of uridine into the acid soluble pool. Therefore, it appears that the low rate of uridine incorporation into RNA by day 2 embryos is at least partially attributable to the low rate of precursor uptake. Since preimplantation mouse embryos develop in vitro in the absence of uridine, the physiological role of the uridine transport system during this period is uncertain. Nonetheless, the preimplantation change in uridine transport is a striking developmental phenomenon and may be important in preparing the embryo for the utilization of exogenous nutrients during postimplantation growth and development.

Circulation and its Distribution in Previable Human Fetuses. Mighael A. Hexmann, Abraham M. Rudolph, Kari Teramo, Cynthia T. BarretT and Niels Raiha, Univ. of California, San Francisco and Helsinki Univ. Central Hosp.

The course of the circulation, distribution of cardiac output and organ blood flow have been extensively studied in fetal lambs. No such information is available in human fetuses. 33 fetuses weighing 12-272 g (estimated gestation 10-20 weeks) were delivered by hysterotomy performed for legal abortion with the mother receiving general anesthesia and $50 \% \mathrm{O}_{2}$. While placental circulation continued, a fine teflon cannula was inserted into the umbilical vein (UV), and nuclidelabeled microspheres were injected (within $3 \mathrm{~min}$ in most fetuses) to measure the distribution of blood flow. $\mathrm{pH}, \mathrm{PO}_{2}$ and $\mathrm{PCO}_{2}$ were measured in arterialized maternal (MA) and in UV and fetal arterial (FA) bloods. Mean values for MA were $\mathrm{pH} 7.47, \mathrm{PCO}_{2} 23$, and $\mathrm{PO}_{2} 183$, for UV pH 7.41, $\mathrm{PCO}_{2} 26$, and $\mathrm{PO}_{2} 60$, and FA pH $7.27 \mathrm{PGO}_{2} 38$ and $\mathrm{PO}_{2} 34$. Distribution of blood flow to each organ was expressed as a percentage of systemic venous return ( $\% \mathrm{CO}$ ) in 4 weight groups $<50 \mathrm{~g}, 51-100,101-150$ and $>150 \mathrm{~g}$. The \% CO to placenta increased from a mean of 16.9 in $<50 \mathrm{~g}$ to 33.1 in $>150 \mathrm{~g}$ fetuses; \% CO to gut rose from 5.5 to 9.2 and to spleen from 0.4 to $0.9 ; \% \mathrm{CO}$ to kidneys fell from 6.5 to 3.2 , myocardium 3.3 to 2.1 , and brain 16.0 to 11.3 . An average of $51.4 \%$ of UV blood passed through the ductus venosus; no significant change with growth was noted. In $<50 \mathrm{~g}$ fetuses $50.7 \%$ of inferior vena caval blood crossed the foramen ovale to be distributed to the upper body, brain and myocardium; this fell to $32.3 \%$ in the $>150 \mathrm{~g}$ group. These studies demonstrate that the pattern of circulation in human fetuses is similar to that of other mammals, but there are quantitative differences in distribution of cardiac output. (Supported by NIH Grant HE 06285).

\section{The Actions of Cardioactive Drugs on Developing} Myocardium. William F. Friedman, Charles Cooper, Tomás Romero, Univ. of Calif.-San Diego, Sch. of Med., La Jolla, Calif.

Clinicians have long recognized age related differences in cardiac pharmacology. These phenomena may reflect altered drug metabolism or disposition in the immature organism and/or an altered sensitivity of fetal and neonatal myocardium per se. The latter possibility was examined by studying the responsiveness to cardioactive drugs of heart muscle isolated from a total of $100 \mathrm{fetal}$, newborn, and adult sheep and swine. The enhancement of cardiac contractility produced by digitalis was significantly greater in newborn than adult heart. However, newborn myocardium required significantly more digitalis to achieve a peak inotropic effect or to demonstrate evidence of toxicity when compared to the adult. Fetal and adult cardiac muscle was equally responsive to isoproterenol, and acetylcholine. Fetal heart was supersensitive to the positive inotropic effects of norepinephrine. At all ages acidosis attenuated the augmentation of contractility produced by norepinephrine. Propranolol exerted a more profound negative inotropic action on fetal than adult heart, although the effectiveness of beta adrenergic receptor blockade by propranolol was equal in fetal and adult myocardium. Glucagon exerted a negative inotropic effect on fetal cardiac muscle, a small positive inotropic effect in newborns, and a marked augmentation of contractility in the adult. Thus, a marked agedependency of the myocardial responses to many cardioactive drugs exists that must be considered in any clinical evaluation of cardiac pharmacology in the perinatal period.

33 Cardiac Responses to Sympathetic and Vagal Stimulation in the Newborn Lamb During Acidosis and Hypoxia. Elliot A. Milgram, Katherine H. Halloran, Norman S.Talner, Alexander G. M. Gampbell and S. Evans Downing, Yale Univ. Sch. of Med., Depts. Path. and Ped., New Haven, Conn.

Heart rate (HR) and left ventricular contractility (VC) responses to sympathetic and vagal nerve stimulation were assessed in 15 lambs from $<1$ to 3 days of during lactic acidemia, hypercapnia and hypoxemia. These were compared with responses under control conditions. In all experiments supramaximal electrical stimulation of the left inferior cardiac sympathetic nerve produced large increases of $\mathrm{VG}$ as measured by the $\mathrm{dP} / \mathrm{dt} \max$ from a given end-diastolic pressure (LVEDP) when HR, mean aortic pressure and cardiac output (Medicon) were held constant. With a $\mathrm{pH}$ of 7.39 the $\mathrm{dP} / \mathrm{dt}$ max increased from 3,000 ( $\pm 155 \mathrm{SE})$ to 4,244 ( $\pm 147 \mathrm{SE}) \mathrm{mm} \mathrm{Hg} / \mathrm{sec}$ during stimulation, while the LVEDP fell from $7.3( \pm 0.73 \mathrm{SE})$ to 5.8 $( \pm 0.79)$. During acidemia the increase $(1,310 \pm 159$ $\mathrm{SE})$ was unchanged. With hypercapnia $\left(\mathrm{PCO}_{2} 69\right.$ $\mathrm{mm} \mathrm{Hg})$ the responses were less $(840 \mathrm{~mm} \mathrm{Hg} / \mathrm{sec})$ than with low $\mathrm{PCO}_{2}(1,300 \mathrm{~mm} \mathrm{Hg} / \mathrm{sec}, \mathrm{p}<0.01)$. Responses during hypoxemia $\left(\mathrm{PO}_{2} 33 \mathrm{~mm} \mathrm{Hg}\right.$ ) were identical to those with normal $\mathrm{PO}_{2}$. Cardiac slowing in response to stimulation of the right distal vagus $\mathrm{N}$ was measured 